\title{
In Memory of Peter Duren
}

\section{Johnny Brown, Martin Chuaqui, Tim Ferguson, Dima Khavinson, Steven G. Krantz, Brad Osgood, Alex Schuster, and Rachel Weir}

\section{Peter's Life}

Peter Larkin Duren (1935-2020), Professor Emeritus at the University of Michigan, died on July 10, 2020. He was a leading mathematician in the field of complex analysis.

William L. Duren, Peter's father, was also a mathematician and received his $\mathrm{PhD}$ from the University of Chicago. He was chair of the Mathematics Department at Tulane University and was a president of the MAA. Peter's mother, Mary Hardesty Duren, received a PhD in zoology from the University of Chicago.

Peter was born and raised in New Orleans. He graduated from Harvard in 1956. Peter enrolled in the graduate program at the Massachusetts Institute of Technology with the intention of studying Applied Mathematics. However, after taking classes from Klaus Roth, Eli Stein, Dirk Struik, Norman Levinson, and Joseph Walsh at MIT and Harvard, Peter realized his interests lay more in the direction of Pure Mathematics. He began working with the classical and functional analyst Alberto Calderón, the cofounder, with Antoni Zygmund, of the theory of singular operators. But Calderón returned to the University of Chicago in 1958, and Peter became a student of GianCarlo Rota, the only MIT faculty member ever to hold the title of Professor of Applied Mathematics and Philosophy. (Rota actually worked in functional analysis before moving to combinatorics.) Peter read Arne Beurling's seminal 1948 paper "On two problems concerning linear transformations in Hilbert space," in which the author characterized the invariant subspaces of the shift operator on $\ell^{2}$. In his doctoral thesis, entitled "Spectral theory of a class of

Communicated by Notices Associate Editor Daniela De Silva.

For permission to reprint this article, please contact:

reprint-permission@ams.org.

DOI: https://doi.org/10.1090/noti2333

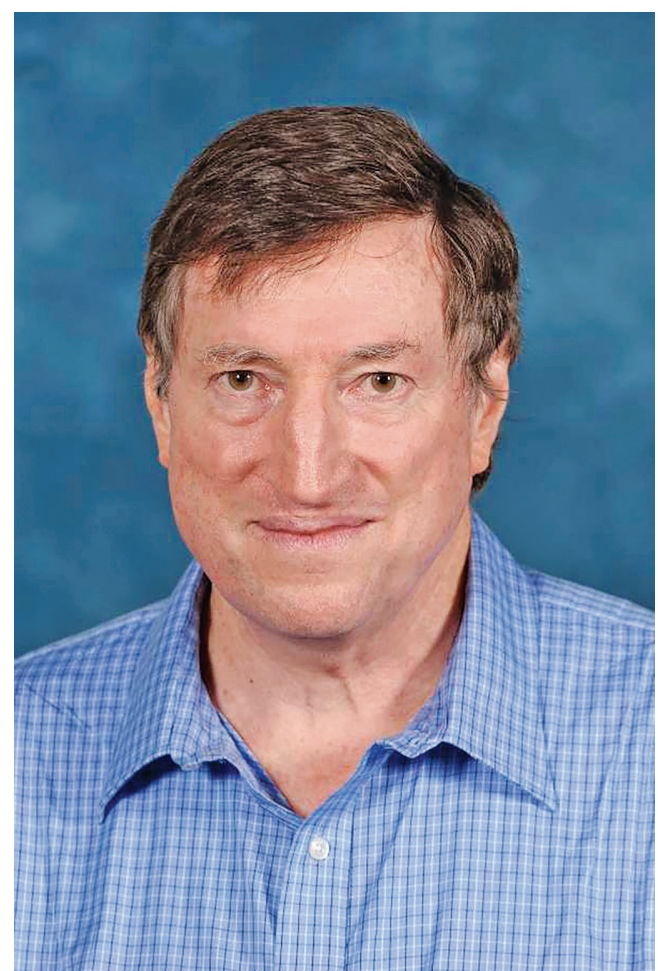

Figure 1. Peter Duren.

non-selfadjoint infinite matrix operators," Peter extended Beurling's result to a larger class of operators. He received his PhD in 1960.

In the fall of 1960, Peter took a postdoctoral position at Stanford University, where he was a part of the Analysis group, which included George Pólya, Gabor Szegő, Charles Loewner, Stefan Bergman, and Max Schiffer. There Peter began a long-time collaboration with Schiffer that led to ten significant papers, the first of which was published in 1962, the last in 1993. 
Peter began teaching at the University of Michigan in 1962, and remained there until his retirement in 2010. He joined a strong Analysis team that included Paul Halmos, Allen Shields, Fred Gehring, and George Piranian and was soon to be bolstered by the arrival of Harold Shapiro. He spent a year at the Institute for Advanced Study in Princeton from 1968 to 1969 , and had visiting positions at Stanford, London, Paris, Maryland, and Trondheim, Norway, among others.

Peter met his wife Gay in college while they were singing in Gilbert and Sullivan operettas together. They were married in 1957 and had two children. Peter and Gay loved to travel together. Some of their favorite destinations included France, the Swiss Alps, Norway, and New Zealand.

Peter was an athlete and relished physical challenges. He played high school basketball and even in his 60s he enjoyed seeking out strenuous hikes in the destinations he visited. As a young father he built a high jump bar for his children and taught them high jumping.

Peter had a number of passions and hobbies, to which he brought the accuracy and precision of a mathematician. Some of his interests were listening to classical music, birding, gardening, photography, stamp collecting, carpentry, and astronomy. He was always a collector and keeper of lists. Some of his more unusual pursuits show his quirky sense of humor. For example, with a somewhat purposeful eccentricity he collected banana stickers. He was fond of performing unsolicited magic tricks. Once, having been advised that he needed to do something unusual and interesting for the few students who showed up to class right before Thanksgiving, Peter performed card tricks for them. He loved box turtles and would keep some as pets in his back yard. He swore that when he fed them, they wagged their tails.

Peter was passionate about academic freedom and civil rights. He was the treasurer on the board of the University of Michigan's Academic Freedom Lecture Fund from 2001 to 2016. This fund brought speakers to campus in honor of the three professors purged by the University of Michigan in the McCarthy era for alleged Communist leanings.

Peter was a very friendly and collegial person and had numerous collaborators (50 listed on MathSciNet!). He was an author or coauthor of over 120 papers and five books. The books are Theory of $H^{p}$ Spaces [Dur70], Univalent Functions [Dur83], Harmonic Mappings in the Plane [Dur04], Bergman Spaces [DS04] (with Alexander Schuster), and the most recent one, Invitation to Classical Analysis [Dur12]. These books have been widely accepted as model examples of mathematical exposition. Several generations of students have begun or will begin their own mathematical journeys after their encounter with one or several of

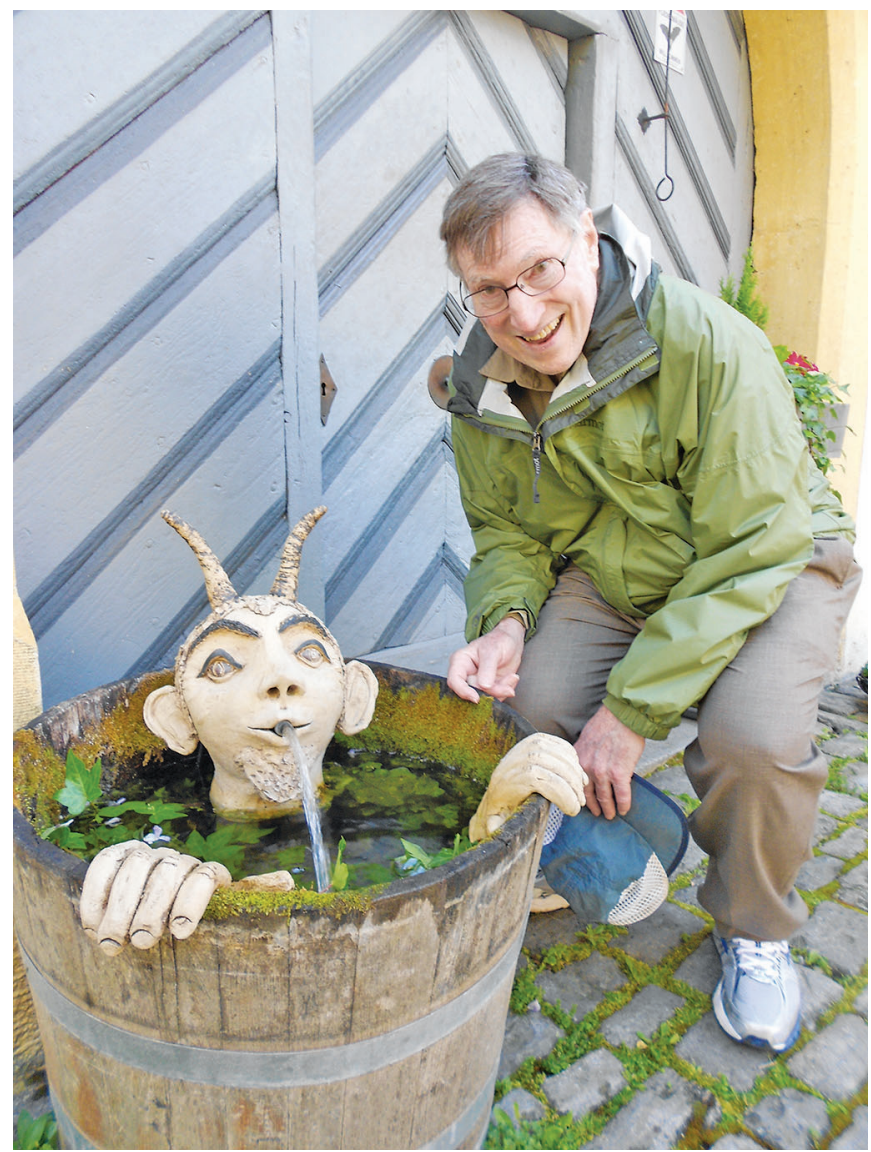

Figure 2. Peter with a statue of a Satyr in Sulzfeld am Main, $20 \mathrm{~km}$ southeast of Würzburg. When he was shown the picture, Peter laughed and commented on the similarity of his appearance with the Satyr's.

Peter's books. Peter loved working with enthusiastic students and advised $25 \mathrm{PhD}$ students.

Peter was a diverse and versatile mathematician. His interests covered a large scope of complex analysis: function spaces, geometric function theory, potential theory, harmonic mappings and geometry, classical analysis, and special functions. It is impossible in a short paragraph to pay a fair tribute to all Peter's contributions to mathematics and the mathematical profession.

In the following collection of reminiscences of Peter's former students, friends, and collaborators, the writers will give some more specifics on Peter's research and his mathematical interests and also show a glimpse of Peter Duren as a person. For all of us who knew him, worked with him, and loved him, he will always serve as a unique example of humanity, integrity, and love for mathematics, life, and friends. 


\section{Dima Khavinson}

It is difficult to squeeze almost four decades of close friendship and collaboration into a couple of pages. Thus, I will try to present Peter Duren, the person and, also, my dear friend and collaborator, through the prism of my experience.

His books Theory of $H^{p}$ Spaces, Univalent Functions, Bergman Spaces, Harmonic Mappings in the Plane, and Invitation to Classical Analysis will speak for themselves to many generations of students to come. The same goes for his over 120 research papers. His masterful writing has been acknowledged and praised by many, as have his many research papers covering the broad scope of complex analysis. But it is equally important to preserve and cherish our memories of Peter as a person, who in our uncertain times should serve as a role model for generations of young scientists.

Up front, I must apologize for perhaps putting this note through too personal a light, but that is how I remember Peter. Thus, so it goes, the way I remember it.

While studying on my own in Moscow in the former Soviet Union, after not having been admitted to Moscow University, I became obsessed with the class of weird domains $\Omega$ in the plane with Jordan rectifiable boundaries for which the derivative of the Riemann mapping of the unit disk $\mathbf{D}$ onto $\Omega$ has a nontrivial singular inner factor. These are called non-Smirnov domains (named after V. I. Smirnov, who actually believed that such domains do not exist). They have a number of peculiar properties, cannot easily be drawn, and for three decades the only known construction of such domains was due to M. V. Keldysh and M. A. Lavrentjev in the 1930s. It is presented in Privalov's book Boundary Properties of Analytic Functions, only available in Russian and German. The Keldysh-Lavrentjev example there was written by G. Ts. Tumarkin, and he personally told me that when he tried to talk to Lavrentjev, in order to simplify the construction and make it more accessible to "mortals," Lavrentjev declined for reasons of health and age. Then, my father, S. Ya. Khavinson, suggested that I look at the beautiful paper of Duren, Shapiro, and Shields entitled "Singular measures and domains not of Smirnov type" [DSS66].

The analytic construction in that paper is so direct, clear, and well-written, that one might say it is taken from "the BOOK." (One of the most exciting and important experiences in my life was meeting and befriending all three authors of that paper.)

Dima Khavinson is a professor of mathematics at the University of South Florida. His email address is dkhavins@usf.edu.
After that, I would read every paper of Peter's that I could get my hands on. Remember that this was the Soviet Union version of Moscow: the only copy of Peter's Theory of $H^{p}$ Spaces classic I could get my hands on was in the Library of Foreign Languages. That is where I spent my last months in the SU reading Peter's exposition of Carleson's proof of the Corona Theorem, the only exposition available at the time: an elegant simplification by Tom Wolffe and, later, by T. Gamelin only appeared in the late 70s.

At Peter's 70th birthday conference in Madrid, M. Stessin told us that all of Peter's books were eventually stolen from Moscow libraries-a clear acknowledgment of the superior quality of his writing.

A few years later in 1984, having recently finished my degree, I got a formal letter from Peter (an actual letter, mind you) inviting me to a special session he was organizing at the winter AMS meeting in New Orleans. From that point, our personal friendship began. In spite of a difference in age, scientific experience, and position in the unwritten ranks of mathematics, Peter always made me feel equal. I am sure it was not my personal privilege: he treated everyone with warmth and respect. Also, I must mention what a treat it was to visit New Orleans for the first time together with Peter, who grew up there. Much later, in 2000, we ended up together again in New Orleans, where Peter was accompanied by Gay and his father Bill Duren. I wish someone had thought of tape recording the stories that were told at the several dinners we had together.

After we started our collaboration, I spent numerous weeks at a time in Peter and Gay's house, participating in their daily routines. Their warm, natural, and comforting hospitality was truly rare. I am sure many complex analysts will remember the big sign over the bathtub in the bathroom on the landing between the first and second floors, "Please, do NOT try and fix the drip!" One can only imagine what experiences Peter and Gay had to endure with mathematicians playing plumbers. We also took the obligatory trips with Peter to the Ann Arbor Farmers' Market on Saturdays.

Our work on dividing out zeros in Bergman spaces prompted by the breakthrough by Haakan Hedenmalm started as an accident. Peter was visiting me at the University of Arkansas to work on a new edition of his $H^{p}$ spaces book, planning to add a whole new section on multiply connected domains. We had just heard Boris Korenblum's exciting recounting of the letter from Haakan and Haakan's breakthrough in the Hilbert Bergman space $A^{2}$. So, we thought to get through it before starting on our $H^{p}$ project. Right there during a nice walk to the picturesque Mount Sequoyah, the biharmonic Green's function and the idea about how the general theory of 
contractive divisors should be done came to us. Simultaneously, Harold Shapiro in Stockholm and Carl Sundberg in Knoxville made similar observations and, as Korenblum called it, "the gang of four" was launched.

That visit of Peter to Fayetteville almost ended in tragedy: I decided to organize a trip to a very nice trout restaurant for the whole special session at the Fayetteville AMS meeting, ignoring the freezing rain that sometimes came down on the Ozark mountains in the spring. It was a miracle that basically every function theorist in the midwest section of the country wasn't killed during that trip. The restaurant's bar, after we finally made it there, had never seen such liquor sales.

I would like to recall here another episode during my sabbatical in Ann Arbor in the fall of 1992. Peter and I decided to walk the 18 mile loop around Silver Lake near Ann Arbor. Little did we know that we happened to have chosen the first day of hunting season. So during the 8-9 hour hike, we were constantly face-to-face with local hunters drinking something that did not look like water from flasks and reacting to two nerdy professors with increasing hostility-at least that was my perception. I attribute our survival and coming out of this adventure unharmed exclusively to Peter's personality and his kind smile directed at strangers-qualities that $\mathrm{I}$, as a true son of the former Soviet Union, do not possess in the least.

Peter and Gay were very accomplished hikers. They loved having adventures and often told stories and showed photos of their hikes in the US, New Zealand, France, Norway, and many other places worldwide. During my stay in Ann Arbor in '92, I partook in their training for a rim-torim hike of the Grand Canyon, practicing on the hill (the only one!) in Ann Arbor's Arboretum. (Since I now live in Florida, I can call that knoll a hill without blushing.) And it helped! They succeeded and repeated that rim-to-rim hike several times.

After Catherine Bénéteau and I were hired by the University of South Florida in Tampa, Peter and Gay visited us many times. They "officially" adopted our daughter Sophie as their granddaughter. These visits were so much fun. As many of his friends knew, both Peter and Gay were avid bird watchers. So visiting Florida was quite special for them, as one does not need to look far around here to find wildlife-it comes to you while you are sitting on the porch. I must tell a humorous story. There is a place near Ann Arbor where sandhill cranes always come to rest in their migration south every late fall. It is that place that for a week in October becomes a focal point of local bird enthusiasts. Peter and Gay took me there on several visits, and the experience was truly unique: all of a sudden out of nowhere, hundreds of cranes fly in and settle for the night, a sort of crane version of Chicago's O'Hare. But of course..., the cranes end up in Florida, Tampa in particular. So, I couldn't help pointing out to Peter all the cranes that we have walking in our neighborhood. You need not drive anywhere to see them, rather you have to be on high alert all the time not to hit them. Peter was slightly disappointed, I thought, so I kept teasing him about it.

At the time Peter and I were obsessing about finding out more about the German mathematician Robert Jentzsch, the author of the famous Jentzsch Theorem about Taylor series, and only known to us as the mathematician with the most consecutive consonants in his last name. After Anne-Katrin Herbig joined us, we found out lots of remarkable facts: the major thing being that Jentzsch was probably better known as a poet in his time, and was yet one more tragic casualty of WW I [DHK08].

Two of the main benefits that I feel mathematics has given me are friendships and collaborations. Collaborating with Peter has always been very special. He had the remarkable ability to give his whole self to whatever project he was working on. Whether it was a research project, a book, editorial work (e.g., his monumental work in co-editing-with S. Zdravkovska-Golden Years of Moscow Mathematics), a historical paper-he was all in. During his long and extremely productive career, Peter covered a spectacularly broad spectrum of analysis-just take a glance at his publications on MathSciNet. One also cannot help but notice the diversity of his coauthors and students: from all genders, all ethnic groups, very different backgroundsthat tells you a lot about what kind of person Peter was, about his integrity, the absolute absence of bias of any kind, and his attentiveness to other people and their problems. He has been and still is a role model for me.

The last time I saw Peter was at a conference in 2017 at one of our favorite places, the Mittag-Leffler Institute in Stockholm. He had been suffering for several years from a very exhausting, debilitating illness. He couldn't lecture anymore, but he and Gay came just because it was my 60th birthday conference. Once again, he taught me a lesson about what friends do. After that, communications became rare, since Peter couldn't really type or talk on the phone. Last summer we learned that he died, thankfully allowed to be with his family for the last few days, in spite of the COVID restrictions.

Peter Duren was one of my closest friends and colleagues. His death is a great loss for mathematics which he served all his life, and a great loss for me personally. I will always love him and miss his friendship, his soft laugh, his sense of humor, his warmth, and his excitement whenever a new project or a new adventure would take shape in front of us. 


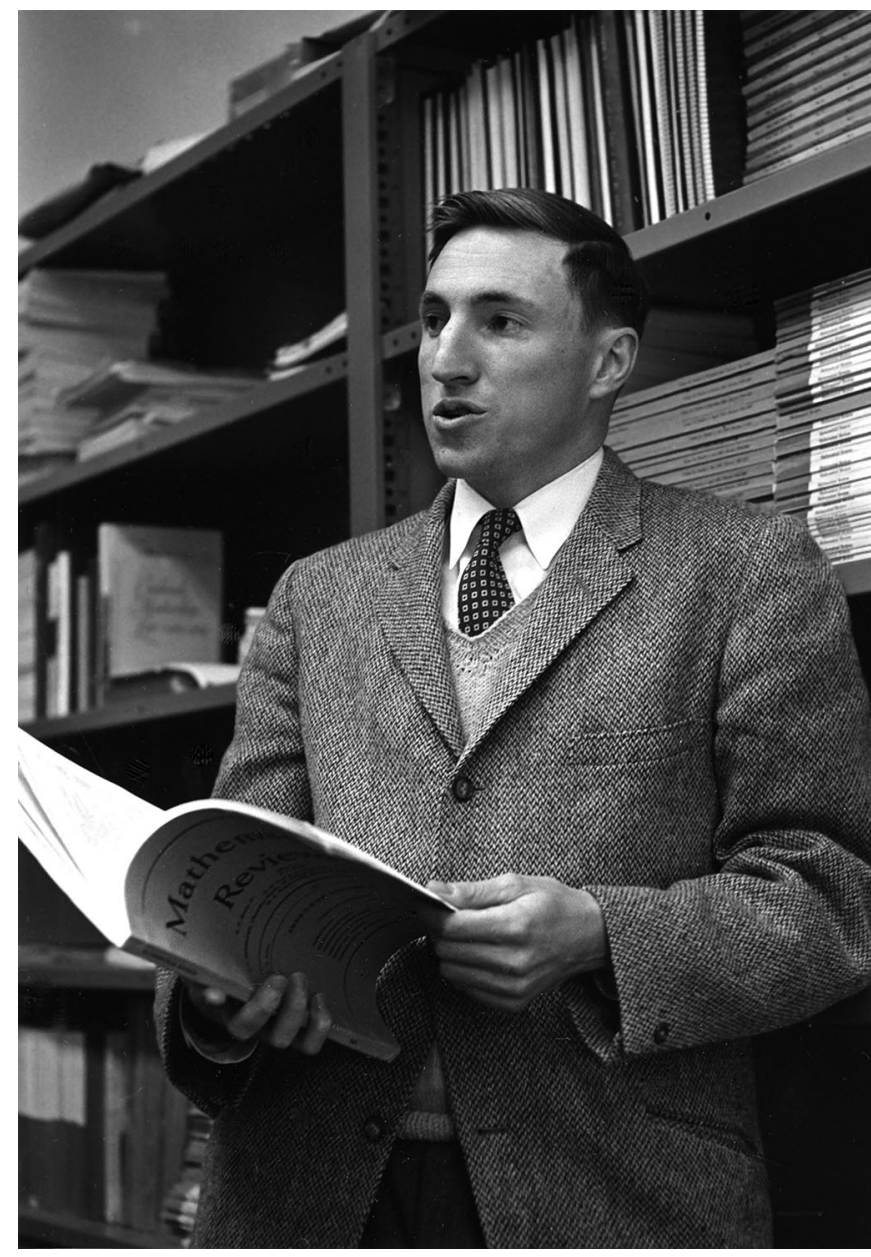

Figure 3. Peter Duren. From the University of Michigan Bentley Historical Library.

\section{Steven G. Krantz}

For many years now, Peter Duren has been a mentor, a role model, and a friend. He was the kind of friend who would tell you when you were making a mistake, and praise you when you did something right.

We all admire Peter for his mathematics and his scholarship. He was also a gifted and effective teacher. He directed $25 \mathrm{PhD}$ theses, which makes him a member of a rather exclusive club. He was a popular undergraduate teacher, and a frequently consulted mentor.

Perhaps the strongest impression that Peter Duren made on me was with his books. There are five of them, all impressive. The ones that had the greatest impact on me were Theory of $H^{p}$ Spaces and Univalent Functions. Both of these books were the right book at the right time. The second of these came out only a few months before Louis de

Steven G. Krantz is a professor of mathematics at Washington University in St. Louis. His email address is sk@wust1 . edu.
Branges proved the Bieberbach conjecture! These books have had, and will continue to have, a lasting impact on modern mathematical analysis.

One notable trait of Peter Duren was that he was willing to talk to anyone about mathematics. Examining his list of collaborators, one can see the universal nature of his tastes. These include Walter Rudin, Kathy Driver, Dima Khavinson, Harold Shapiro, M. A. Schiffer, Allen Shields, J. Clunie, and Ian Graham. Clearly Peter was conversant in all parts of modern analysis.

Of course Peter had a number of notable theorems to his credit. One of the most famous, and most frequently cited, was the one proved with Romberg and Shields that characterized the duals of the $H^{p}$ spaces [DRS69]. Peter had a number of very good papers on Schlicht functions, and a number of papers on Hardy spaces. He was an expert on the Schwarzian derivative. He touched many different parts of complex and real analysis and functional analysis.

Peter was a dynamic and charming individual. He had many interests and many passions. He liked to tell people that he was once dandled on the knee of Albert Einstein (his father was a visiting scholar at the Institute for Advanced Study). He will be missed by his students, his colleagues, his friends, and his family.

\section{Alex Schuster}

I chose Peter to be my thesis advisor at Michigan before I ever took a class from him. I was interested in the interplay between complex and functional analysis, and Peter was the only member of the department working in a related area. He was really the only choice for me, unless I was willing to change areas, which I was not. I was very lucky, because Peter was an excellent advisor and ended up having a profound and positive effect on my development both as a mathematician and a teacher.

Peter's style as an advisor was definitely "hands off." He would be willing to meet with me whenever I had questions, but he always encouraged me to look for the answers myself before coming to him. When it came time to select a thesis problem, he simply gave me a copy of Kristian Seip's seminal paper characterizing sets of sampling and interpolation sequences for Bergman spaces. "Tell me what you think of this, Alex," he told me. This eventually turned into a basis for my thesis. Peter's philosophy of encouraging his students to search for their own problems has served me well and allowed me to gain my independence very early on in my mathematical career.

Alex Schuster is a professor of mathematics at San Francisco State University. His email address is schuster@sfsu.edu. 
Peter was very social and introduced me to a great many mathematicians in the field while I was still a graduate student, encouraging me to attend conferences and seminars and even give talks myself. He ran an analysis seminar and always invited me to dinner with the speaker. I was not yet aware of the importance of networking, but I definitely benefited from these opportunities when applying for jobs.

In the fall of 1996, Peter visited Kristian Seip at the Norwegian University of Science and Technology for two months. I was lucky enough to be able to accompany him. It was a great opportunity on many levels. I spent that time working with both Peter and Kristian and was able to learn a great deal. Part of the visit consisted of Peter giving a short course on Bergman spaces, for which he prepared a set of notes. When we returned to Ann Arbor, he asked me to help expand the notes into a full-length monograph, which I readily agreed to. We collaborated on the project for several years afterwards, mostly during the summers when I would visit Michigan. Peter was an outstanding expositor of mathematics, and writing a book with him was a great pleasure. Eventually, in 2004, Bergman Spaces [DS04] was published.

Peter was a great mentor and friend, and I regret that our communication dwindled a bit in recent years. I will miss him.

\section{Tim Ferguson}

I was Peter Duren's last PhD student. I first met Peter in the spring of 2006 when I was a prospective grad student, and I enjoyed meeting him. My first substantial interaction with him was a year later, when I began to think about finding an advisor. I met with Peter and he gave me a copy of his $H^{p}$ spaces book to keep and read over the summer. He also let me borrow a copy of his Bergman Spaces book with Schuster, which he let me keep once I became his student. I remember enjoying our meeting, and I found the topics in the books very interesting. I became his student in the fall of 2007.

Peter and I spent many hours in his office talking about math. He didn't mind that most of it was only distantly related to my dissertation; he just enjoyed talking about math. He was always happy to talk when I came to his office, even though I often just showed up at random times. He loved to talk about results in classical analysis. I have memories of discussing Bessel functions and much of the material from his book Invitation to Classical Analysis. Another discussion I particularly remember was on how to

Tim Ferguson is an associate professor of mathematics at the University of Alabama. His email address is tjferguson1@ua. edu. integrate $\int_{-\infty}^{\infty} e^{-x^{2}} d x$ using a contour integral. To do this, one notes that $e^{-(z+\sqrt{\pi i})^{2}}$ is closely related to $e^{-z^{2}}$, and one uses this fact to find a related function to integrate over a parallelogram having one pair of sides bounded and one pair of sides going to infinity. Cancellation in the resulting integral gives the value for the original integral.

I also remember Peter's excitement in sharing with me how he learned that the commonly seen portrait of the famous mathematician Adrien-Marie Legendre was not actually him - it was actually the portrait of the politician Louis Legendre. The only known surviving picture of AdrienMarie Legendre is a caricature of him that appears on the same piece of paper as a caricature of Fourier. Peter wrote an article for the 2009 Notices of the AMS detailing how this was discovered [Dur09]. Peter was interested in the history of mathematicians. He also knew French, which is perhaps one reason he became interested in the Legendre portrait. This reminds me of a funny story. Peter wrote the French language exam the first semester I decided to take it. I knew no French, but I had heard the grading was easy and I was hoping my Latin knowledge could get me through, along with the fact that we could use a dictionary. Unfortunately for me, beyond the fact that this was a bad plan, Peter made the exam harder than I expected, and so I failed. Later he asked me if I knew French. When I said "no, just Latin," he said something along the lines of "Good. You did very badly on the exam. I was afraid you knew French and were very bad at it, but since you just know Latin you did well." I studied French by getting a grammar book and reading Cauchy's Cours d'Analyse for a few weeks. I passed the French exam the next semester. Someone else had written it and it was much easier, but I think I could have passed one of Peter's exams.

Peter was exceptionally kind and caring as an advisor. One day when it was pouring rain and I forgot a coat, he lent me an old rain coat of his. Whenever my wife (who was then my girlfriend and later fiancée) came to visit, he was always very kind to her as well, and she has many fond memories of him. When he found out that she loved turtles and was studying them for her Master's degree, he found an old article about his father that mentioned Peter (then a child) and his pet box turtle, Boxy. I remember his excitement in showing it to her. He also gave her good advice on choosing where to get her PhD (even though it was not in math). I remember I saw Peter once at a JMM after I graduated. He told me that he was excited to hear about what I was doing mathematically, but was more excited when I told him that my wife and I were expecting our first child.

My last visit with Peter was in April of 2019. He had difficulty speaking and moving, but his mind was still good. 


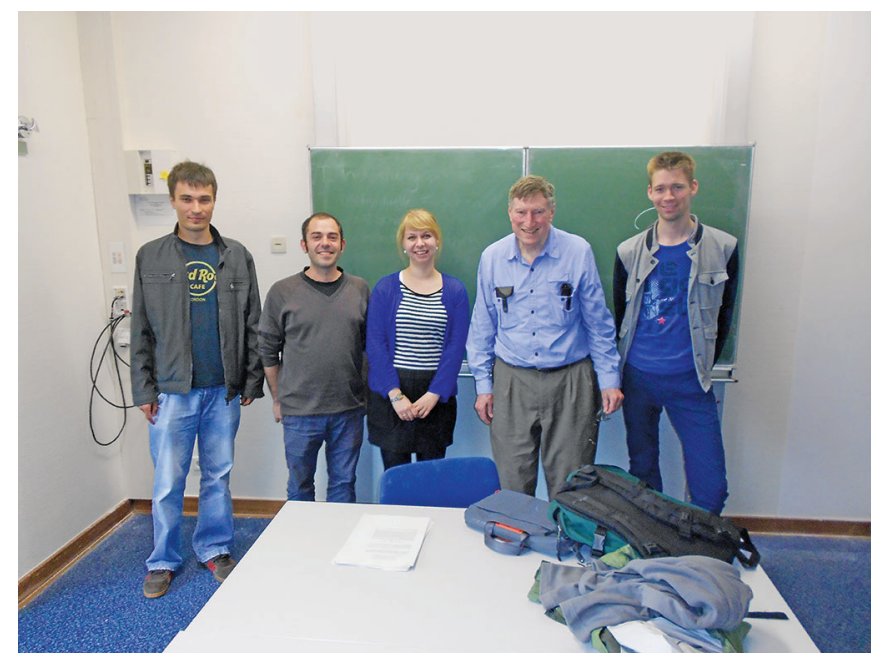

Figure 4. Peter with some of the younger members of the complex analysis group in Würzburg. They are, from left to right: Mihai lancu, Iason Efraimidis, Julia Diana Koch, Peter Duren, and Sebastian Schleissinger.

As before, he was excited to hear of my professional accomplishments, but was more excited to see pictures of my family.

Peter made a great impact on me. He taught me the importance of networking, meeting colleagues, and going to conferences. He took me along with him to many of the annual SEAMs (Southeastern Analysis Meetings), where I met many colleagues. He taught me to write well by carefully correcting drafts with his red pen. (Even now, when my wife looks at something I have written and tells me I have too many commas, we both remember Peter, since he always said the same thing.) When I began to work on extremal problems in Bergman spaces for my dissertation, he translated Ryabykh's paper on Hardy space regularity of Bergman space extremal functions from Russian for me. It must have taken him a good deal of work, but he did not hesitate to do it.

Peter was a great advisor and friend to me and many others. I greatly miss him.

\section{Rachel Weir}

It was completely by chance that Peter Duren became my $\mathrm{PhD}$ advisor, but that one chance has influenced my career in so many ways for which I will always be grateful. As an international student, I started graduate school at the University of Michigan not even knowing exactly where Michigan was, let alone the level of the department that I was lucky enough to be joining. Influenced by two professors at the University of Auckland (Norm Levenberg and Gaven

Rachel Weir is a professor of mathematics at Allegheny College. Her email address is rweir@a11egheny.edu.
Martin, both U-M grads), I planned to work with one of the many several complex variables experts at Michigan. However, due in part to a complex analysis course that I took with Peter, I soon discovered that one complex variable results were what excited me most. After I became his $\mathrm{PhD}$ student, we had many enjoyable and productive mathematical discussions; a highlight was our common excitement every time we found a connection between hypergeometric functions and the Bergman space.

Peter also showed me how to be a supportive and kind mentor. Soon after I started working with him, he began taking me to conferences and introducing me to people who had previously just been names on papers for me. Those connections led to many opportunities for me, but also started to illuminate who he was mathematically, as a researcher and author, and how much he was respected in the mathematical community.

Many other moments of kindness stand out for me. The time that one of my classmates, also my roommate at the time, fainted during an exam in one of Peter's classes. Peter immediately called his wife, Gay, and together they drove my roommate home while I rushed ahead on my bike to meet them at our apartment. The wedding gift shopping trip to Home Depot with Peter when he helped me fill a cart with the tools that I didn't know I would need as an adult. (Just this year, a tree was toppled in my front yard during a storm and I cut it up using one of the saws that Peter bought me; the same saw that seemed like an unnecessary purchase sixteen years previously.)

When my mother and sister came from overseas to attend my graduation, Peter took us out for a celebratory dinner at the Gandy Dancer, a fancy Ann Arbor restaurant that was beyond the means of a graduate student. A similar dinner had happened, this time with Peter and some of my graduate school friends, on the day that I successfully defended my thesis. For someone far from family, Peter became an honorary relative, eventually proudly displaying a picture of my daughter on his piano.

Peter was an exceptional writer, meticulously focused on finding the perfect phrases, and working with him was, as it turned out, the only writing training I received beyond high school. Fortunately, just having Peter's voice in my head has been enough to guide me and I share his advice with my own students. I think of Peter whenever I comment on a student's senior project, covering the draft with notes just as Peter did for the many drafts of my PhD thesis. I remember him teasing me about my liberal and unnecessary use of commas every time I'm editing a piece of my own writing and the copy of Strunk and White that he gave me is still on my bookshelf (their advice to "Omit needless words" often floats through my head). 
My one regret is the years that I lost with Peter as I struggled with coming out and as I also worried that I had disappointed him by choosing to teach at a liberal arts college rather than a research university. Fortunately, I was able to reconnect with Peter and Gay a few years ago and belatedly realized that he would always support me; if anything, he felt as though he had let me down somehow. I visited Peter several times over the last few years, most recently in February 2020, and while it wasn't always easy to communicate with him as a result of his illness, I was so grateful to have that time with him. Peter was a model of what an advisor and mentor can be. He believed in me more than I believed in myself and always wanted the best for me. Just like that saw that he gave me sixteen years ago, he gave me the tools to support my own students in the same kind and giving way.

\section{Brad Osgood}

I was a student of Fred Gehring but my first contact with the Michigan mathematics department was through Peter Duren. I was writing an MS thesis on quasiconformal mappings with Zeev Nehari at Carnegie-Mellon. It was on Nehari's recommendation that Michigan be the next step, working with Fred, but on the spur of the moment, and with me in the room, he called Peter. As I remember, in abridged form it went something like this:

Nehari: I have a good student who should come to Michigan.

Peter: Good to know. Has he applied?

Nehari: You don't understand, he should come to Michigan.

Peter: I'll look forward to his application.

Nehari: And he needs money.

Peter: That's part of the application.

Nehari: He needs money.

Peter liked to remind me of that conversation.

My stay at Michigan was fairly brief, 1976-1980. It was a marvelous time to study complex analysis: so many students, so many faculty and visitors, so many courses and seminars. After Fred Gehring, the mathematician who had the most influence on me was Peter Duren. His teaching, his writing, his dedication and taste, his encouragement and empathy, all left a lasting impression.

I took one course from Peter, on $H^{p}$ spaces, based on his celebrated book. The course was a model of clarity and inspiration, seamlessly knitting together ideas, techniques, and results. We stopped short of the last chapter on Carleson's proof of the Corona Theorem (according to Peter,

Brad Osgood is a professor of electrical engineering at Stanford University. His email address is osgood@stanford.edu. "best not done in public") and instead finished with Don Sarason's new notes on BMO. That was an eye-opener.

Mostly there were seminars and discussions on univalent functions, partly guided by Peter's working on his book on the subject, published by Springer in the Grundlehren series. Oh, I love that book. All the highlights save one are there: the basics, the Loewner equation (enjoying a renaissance), special classes of univalent functions, and perhaps most of all a particularly lucid treatment of the Schiffer variation (waiting for a renaissance), which Peter learned first-hand from Schiffer himself. What's missing? Peter's book had a copyright date of 1983, shortly before the proof of the Bieberbach conjecture by de Branges in 1984 ! This was not the first time something like that happened - Peter's book Theory of $H^{p}$ Spaces came out just a year before Fefferman characterized the dual of $H^{1}$ as BMO. For an appreciation and summary of Univalent Functions I refer to a review of Peter's book by $\mathrm{Al}$ Baernstein in the Bulletin, January 1985 [BI85].

Many of our conversations took place in Peter's office in Angell Hall. His office was a shrine to the accumulation of stuff. I have a story about that. One day in 1996 Peter decided to make a serious attempt at cleaning up (don't we all). In the balance was whether to jettison some old $\mathrm{PhD}$ theses that were taking up space. He lingered over one and decided to keep it-a fine thesis, though long ago Peter had lost touch with the student, whose primary advisor was Allen Shields. I mention the event and the year because, shortly after, the news broke that Theodore Kaczynski had been arrested as the notorious Unabomber. In a very somber interview, Peter appeared on "Nightline" together with George Piranian to talk about Kaczynski's student days at Michigan; certainly not the way any mathematician would choose to have their fifteen minutes of fame.

Peter's interests had been gradually shifting to harmonic mappings in the plane, and this led to at least two fortunate events. The first was Peter writing a book on the subject, published by Cambridge in the Tracts in Mathematics series. (A confession: I was supposed to review the book for the Bulletin, but I didn't. So let me take this occasion to apologize, again, and to say read it. You'll enjoy it. It's another superb exposition.) The second was most fortunate for me personally, for it led to a long, productive collaboration with Peter and Martin Chuaqui. We wrote a number of papers developing properties of a generalization of the Schwarzian derivative to harmonic mappings, including criteria for injectivity and quasiconformal extensions. This showed that the theorems of Nehari and of Ahlfors-Weill have natural generalizations to lifts of planar harmonic mappings to minimal surfaces. Separate from that program, we even dabbled in some aspects of 
univalent functions, including results on the prevertices of Schwarz-Christoffel mappings-hard to give up the classical heritage. There's something special about becoming a collaborator with one's teacher. It was most fortunate, indeed.

I feel I should say a little about another of Peter's contributions, namely his editorial work. One example is the three-volume collection of essays on A Century of Mathematics in America published by the AMS in the late 80s. Getting so many to contribute so much, and exercising just enough editorial control, was no easy feat. A second example, one in which I played a minor role and knew something of the backstage work, was the two-volume selected papers of Max Schiffer that appeared in 2013, published by Birkhäuser. Larry Zalcman was coeditor. It's a wonderful selection made even more useful by expert commentaries, several of which were written by Peter. I know that Peter was proud of how the Selecta turned out, and felt that he had paid proper tribute to a man he was so close to professionally and personally.

I hope this and the other essays give a sense of how important Peter Duren was to so many people, and of his contributions to mathematics. Such a warm and kind man. Such a fine mathematician. Such a friend.

\section{Johnny Brown}

I came to the University of Michigan in the fall of 1973, full of energy and optimism but very shy. I first met Peter as my instructor in complex analysis and my life was forever changed. His enthusiasm and love for the subject clearly made an impact not only on me but also on other students in that class. After his course, I knew complex analysis would be my research area and I knew I wanted to work with Peter. I could listen to him for hours. Clearly brilliant, he spoke softly and sometimes I had to lean in to hear but I learned something new and valuable with every encounter. In those days there were no manuals or guidelines on how to ask a professor to be your advisor so I took every course that Peter offered. I officially became his student when he gave me a paper he was reviewing and asked if I could do better. He was a remarkable advisor and mentor. In addition to me he had two other students at the time, Anna Tsao and Y. J. Leung. Brad Osgood, Janice Walker, and Mike Robinson were also considered part of our group, even though they had other advisors. We all became close friends which helped tremendously while navigating grad school. Peter had a network of friends worldwide and invited many noted mathematicians to visit the

Johnny Brown is a professor of mathematics at Purdue University. His email address is brown00@purdue.edu. department. There were typically parties and receptions and our group was almost always invited. No one directly told us about the importance of networking but he was making it happen and it happened frequently. One such encounter still stands out in my memory. I had just read an old paper of Max Schiffer and there was an argument that wasn't quite clear to me. Coincidentally, Peter had invited him to Michigan and had asked me to come to his office. I was awestruck at the meeting and when I asked him about the paper, he reproduced his entire paper on Peter's blackboard. I had gotten a private lesson from Max Schiffer! All of his students had access to the people he invited to campus. In 1976, he took the three of us to our first mathematics conference (Conference in Honor of S. M. Shah, University of Kentucky). I still have that black and white conference photo on a shelf in my office to this day. It was a who's who list of mathematicians, some of whom I'd only heard about or read their papers or studied their books. Once again he provided an opportunity for us to network with world-renowned mathematicians. Only now when I look back can I really appreciate how truly amazing those experiences were.

Peter treated everyone with dignity and respect. Though currently diversity and fairness are at the forefront, Peter was ahead of his time back then. Diversity was a slowly emerging process back in the early 70s. To put it in context at Michigan, I remember there being two bathrooms on our floor in Angell Hall - men and faculty men. However there were several female graduate students and some nontenure track female faculty in the department. Maxwell Reade recruited a good number of African-American graduate students and also served as a mentor. Hence there was diversity present. Peter was comfortable around any of us and treated us all the same. Perhaps growing up in New Orleans played a role but I think it was just who he was. He also had a way of inspiring us. For example, following his love for teaching and his style helped me when I had to teach my very first class. I walked into my crowded classroom, the only person of color in the room, and one student looked at me and then immediately stood up and walked out. From that moment on I knew I had to be the best instructor I could be, enjoy what I was doing, and convey that excitement of mathematics to my students-like Peter.

He included me in many activities and never made me feel like an outsider. Even as a minority graduate student back then I felt like a part of the department. On several occasions I was his straight man for a certain card trick he loved to perform at parties. We did it so many times together he gave me a similar trick deck which I still have. He invited us to activities outside the department as well. He would for example invite some of us to run with him 
in the annual Dexter to Ann Arbor race, but we were not as fit as he was. He and Gay graciously invited me to their home several times. Once I helped him gather greens from his garden for the salad we had for dinner that night. He knew how to be a good advisor and it seemed to come naturally to him. He was the most gentle, kind, and generous person I knew.

For several years after graduating, some of our group would return to Ann Arbor to visit during the summer and I would often stop by to see him. On a couple of occasions he invited me back to give talks and he kept up with my progress over the years. He has received many honors and accolades throughout his career, so Y. J. Leung and I were extremely honored to be guest editors for the special issue of Complex Analysis and Elliptic Functions dedicated to Peter on his 70th birthday. He was pleased and so were we. I regret not having written a paper with him. The last time I saw Peter was at his retirement celebration. It was wonderful seeing so many of his students and colleagues there to both honor and thank him. It is abundantly clear that Peter's impact and influence is widespread and deep and we are all fortunate for the time he shared with us.

\section{Martin Chuaqui}

It is not easy to put in a few pages the work of Peter L. Duren, his multiple contributions in various areas of complex analysis, his constant pursuit of knowledge to share with colleagues and younger generations, his genuine love for his work, and his personal integrity. I am grateful for the opportunity to have known him for more than 20 years as a collaborator and as a friend.

I first met Peter in person in 1989 when I was working on the final parts of my doctoral thesis at Stanford. It was one of his last visits to the place of his first appointment in 1960 as a postdoc, a very different time and era that exemplifies Peter's distinguished career of more than half a century. I was in my graduate student office when he came in. We greeted and in a matter of minutes we were engaging in a mathematical discussion concerning my thesis. Calm, interested, and attentive were my first impressions of him, features that would not change over the years when I spoke with him. We discussed univalence criteria and the Bergman kernel on domains in the complex plane that had come up briefly in my study. The interaction was easy and enjoyable.

But that had not been the first time I had spoken with Peter, since years earlier we had been on the phone when he was a member of the graduate admissions committee

Martin Chuaqui is a professor of mathematics at the Pontificia Universidad Católica de Chile. His email address is mchuaqui@mat.uc.c1. in Michigan and I was trying to decide where to go to graduate school in the US. His visit to Stanford in 1989 was motivated by his longtime and fruitful collaboration with Max Schiffer, whom he met in 1960, triggering his interest in conformal mappings. Stanford had been and remained a remarkable center for analysis and complex analysis, and Peter had the chance to meet most of the mathematicians contributing to this golden age: Szego", Schiffman, Spencer, Schaeffer, Royden, Loewner, Pólya, Bergman, Schiffer, Garabedian, and Cohen, among others I may be forgetting. I heard Peter tell many stroies from that period on several occasions.

After his postdoctoral position at Stanford, Peter and his lifelong companion Gay went to Ann Arbor, Michigan, where they would remain. Their house was some 20 minutes away from campus by foot in a very quiet neighborhood south of the central campus. For decades, when weather permitted, Peter would walk back and forth from home to the mathematics department, and I shared the different routes with him many times. The house is still there, located on Baldwin Avenue facing the beautiful Burns Park, where people gather over the weekend to play baseball and other sports. Peter and Gay's children would also play there, and went to elementary school just a couple of blocks away on the other side of the park. This part of Ann Arbor remains relatively unchanged, unlike downtown and especially around the central campus where development has dramatically changed the nature of the city. More than once, Peter and I commented on these noticeable transformations that had come along with the disappearance of traditional stores like the White Market and the Village Corner, not to mention the abrupt changes in leasing policies near campus that have made short term visits much more difficult.

Michigan was to become a leading center for analysis and complex analysis on its own, with iconic figures such as Shapiro, Shields, Piranian, Gehring, and, of course, Peter. It was here where he started to build his enormous legacy in mathematics. A superb writer, Peter left behind extraordinary books on $H^{p}$ and Bergman spaces, univalent functions, harmonic mappings, and his last masterpiece on an array of unique topics in classical analysis that are nowadays rarely present in an undergraduate curriculum. His book on harmonic mappings has brought new life to the subject and offers a very complete account of the theme, describing local and global properties, linear invariant families, extremal problems, coefficient estimates, Riemann mapping analogues, and the connection with minimal surfaces. During his career Peter remained interested and continued to investigate many of these topics, some of them touching upon functional analysis, the subject of his doctoral dissertation at MIT. I would hear from him about 
the still not completely resolved problem of the invariant subspaces of Bergman spaces.

Years later we met at the 1998 Sectional Meeting of the AMS in Louisville, and at the time Peter was working on the last chapters of the book on harmonic mappings. He came up to Brad Osgood and me inquiring about a possible extension of the definition of the Schwarzian derivative for such mappings. We sat down in an empty conference room, probably for not longer than an hour, while Peter explained some basic issues about the subject. Eventually we were led to the Weierstrass-Enneper representation, and there it was, finally something conformal! This seemed important since it allowed one to apply the concept of the Schwarzian derivative for conformal mappings on manifolds developed by Osgood and Stowe. It took about one year to craft these ideas and the heart of the paper, and up to this date it amazes me how a single question, innocent in appearance, can lead to a collaboration of nearly two decades.

Peter visited the Catholic University in Chile in January of 2004, and we worked together for about three weeks, studying certain classes of convex and starlike harmonic mappings. By the end of the second week Gay had already arrived, and after the mathematics was finalized, they left for one of their principal hobbies of sightseeing and hiking, visiting Tierra del Fuego and the Galapagos Islands. Later on, they would relate the wonderful experience of the sight of the Andes mountains on the flight to Punta Arenas on a day with clear skies. I had the opportunity to look at their pictures in July of the same year during my first summer visit to Ann Arbor. I was treated to their warm hospitality and company time and time again. More often than not, Brad would join us to complete the crowd, and Peter was very happy with our company. The overall mood was ideal and I cherish the memories of those occasions. We took numerous walks through the engineering arch to go to the Shapiro Library in search of some book or paper that was always there to be found. There were also many walks to the Arboretum, conversations about society and academic life, and lively dinners at their home. The mathematical collaboration had led to great affection and friendship. We always had fun together in and out of the office. Peter was a very sensitive person with a great sense of humor. He was always active on different fronts, from taking care of his vegetable garden to promoting the Freedom Lecture with a deep sense of duty. He was passionate about mathematics, inquisitive, striving for perfection, deep in his analysis, and very incisive. In each new project it was evident that whatever the task to be accomplished, the manner in which it was done was almost as important as the matter itself.
Stemming from the new definition of Schwarzian derivative, our work drifted into injectivity criteria for harmonic mappings, principally their lifts to minimal surfaces, and various forms of homeomorphic or quasiconformal extensions. It was around that early time of our collaboration that we became aware of the connection with Ahlfors' remarkable definitions of Schwarzian derivatives for curves, which were to become fundamental later on. The match with the conformal Schwarzian was quite striking.

During those years we also found various detours into geometric function theory, mainly convex and concave mappings as well as Schwarz-Christoffel mappings. We were also led to various applications of comparison techniques for ordinary differential equations on the real line and on complex domains.

During my summer visits, Peter would usually have other visitors or faculty members in collaboration. Among them was Marijose Martin, an academic granddaughter of Peter through his student Dragan Vukotić in Madrid. She was starting to become interested in the subject of harmonic mappings, and that year coincided with an unusual number of other visitors that Peter found a way to fit into his agenda. Later on, I became acquainted with AnneKatrin Herbeg, who at the time was a postdoc at Michigan. Although she specialized in several complex variables, she and Peter became close and were collaborating on an article about the remarkable mathematician Robert Jentzsch [DHK08]. I learned from that article about the surprising theorem of Jentzsch on the points of accumulation of the zeros of partial sums of a power series.

Peter often shared stories with us about encounters over the years with some notable figures of the mathematical community, shedding light into the more intimate fiber of this scientific society. For a long time, I benefited from the annual letter he and Gay would send to friends about their activities and whereabouts during the last twelve months. Peter's academic career had started in the early sixties and continued through the eighties and into the twenty-first century, adapting to the changes of time only in form. He was an extraordinary person that one would get to know from his actions as much as from his words.

My visits to Ann Arbor were interrupted in 2013. Years earlier Peter had finally undergone knee surgery and had a difficult recovery. When I returned in 2017 he had already started to be affected by Parkinson's disease, which he confronted with enormous strength and courage. The illness took a severe toll on his overall vigor, and while it made communication quite difficult, his mind remained unaffected. He was happy to see Brad and me, and managed to join us in the office on more than one occasion, eager to hear and engage with what we were doing. Soon after, Gay and Peter would move into the retirement home where 
Gay was able to provide him with more adequate care. We also visited them in 2018 and 2019, and although Peter enjoyed our company, the disease was not receding. The news of his passing last year made me, along with many other people, very sad. Through his papers and books, his collaborators and friends, his students and family, Peter leaves behind his mathematical legacy and attitude towards life that will stay with us.

\section{References}

[BI85] Albert Baernstein II, Book Review: Univalent functions, Bull. Amer. Math. Soc. (N.S.) 12 (1985), no. 1, 158-165, DOI 10.1090/S0273-0979-1985-15330-3. MR1567534

[Dur70] Peter L. Duren, Theory of $H^{p}$ spaces, Pure and Applied Mathematics, Vol. 38, Academic Press, New York-London, 1970. MR0268655

[Dur83] Peter L. Duren, Univalent functions, Grundlehren der Mathematischen Wissenschaften [Fundamental Principles of Mathematical Sciences], vol. 259, Springer-Verlag, New York, 1983. MR708494

[Dur04] Peter Duren, Harmonic mappings in the plane, Cambridge Tracts in Mathematics, vol. 156, Cambridge University Press, Cambridge, 2004, DOI 10.1017/CBO9780511546600. MR2048384

[Dur09] Peter Duren, Changing faces: the mistaken portrait of Legendre, Notices Amer. Math. Soc. 56 (2009), no. 11, 1440-1443. MR2590729

[Dur12] Peter Duren, Invitation to classical analysis, Pure and Applied Undergraduate Texts, vol. 17, American Mathematical Society, Providence, RI, 2012. MR2933135

[DHK08] Peter Duren, Anne-Katrin Herbig, and Dmitry Khavinson, Robert Jentzsch, mathematician and poet, Math. Intelligencer 30 (2008), no. 3, 18-24, DOI 10.1007/BF02985374. MR2437196

[DRS69] P. L. Duren, B. W. Romberg, and A. L. Shields, Linear functionals on $H^{p}$ spaces with $0<p<1$, J. Reine Angew. Math. 238 (1969), 32-60.MR259579

[DS04] Peter Duren and Alexander Schuster, Bergman spaces, Mathematical Surveys and Monographs, vol. 100, American Mathematical Society, Providence, RI, 2004, DOI 10.1090/surv/100. MR2033762

[DSS66] P. L. Duren, H. S. Shapiro, and A. L. Shields, Singular measures and domains not of Smirnov type, Duke Math. J. 33 (1966), 247-254. MR199359

\section{Credits}

Figure 1 is courtesy of Michigan Photography.

Figures 2 and 4 are courtesy of Iason Efraimidis.

Figure 3 is copyrighted by Regents of the University of Michigan. This work is subject to a Creative Commons Attribution 4.0 International License.
CALL FOR NOMINATIONS

\section{Nemmers Prize}

in Mathematics $\$ 200,000$
Northwestern University invites nominations for the Frederic Esser Nemmers Prize in Mathematics, to be awarded during the 2021-22 academic year. The prize pays the recipient $\$ 200,000$.

Candidacy for the Nemmers Prize is open to those with careers of outstanding achievement in their disciplines as demonstrated by major contributions to new knowledge or the development of significant new modes of analysis. Individuals of all nationalities and institutional affiliations are eligible except current or recent members of the Northwestern University faculty and recipients of the Nobel Prize.

The 2022 Nemmers Prize recipient will deliver a public lecture and participate in other scholarly activities at Northwestern University for 10 weeks during the 2022-23 academic year.

Nominations will be accepted until December 31, 2021. The online submission form at nemmers.northwestern.edu requires the nominee's CV and one nominating letter of no more than 1,000 words describing the nominee's professional experience, accomplishments, and qualifications for the award. Nominations from experts in the field are preferred to institutional nominations; selfnominations will not be accepted. Please email questions to nemmers@northwestern.edu.

The Nemmers Prizes are made possible by a generous gift to Northwestern University by the late Erwin Esser Nemmers and the late Frederic Esser Nemmers.

\section{Northwestern}

Nemmers Prizes • Office of the Provost Northwestern University • Evanston, IL 60208

\section{nemmers.northwestern.edu}

Northwestern University is an equal opportunity, affirmative action educator and employer. 